\title{
Homenagem Póstuma ao Professor Sylvio Marcondes Machado*
}

1. Em nome da Congregação desta Faculdade, por designação de seu diretor, venho lhes falar de Sylvio Marcondes, que morreu há quarenta dias, na noite de 3 de outubro.

Muitos nesta Casa foram seus amigos, alguns por bem mais tempo do que eu, e podiam, todos certamente, com mais acerto e mais propriedade, dizer, nesta homenagem, da têmpera de seu espírito e da qualidade de sua inteligência. Coube-me essa honra, que me apressei a aceitar, tomando afoitamente o lugar de meus melhores.

Por longos anos tivemos no mesmo conjunto os nossos escritórios, e no trato constante de nossas vidas profissionais, que corriam paralelas, logo aprendi a respeitar o seu caráter íntegro e a admirar a sua capacidade de jurista. Não fui seu aluno - formei-me nesta Escola antes de ele nela ingressar como professor - mas foi meu mestre num sentido muito mais profundo e muito mais real, mestre de vida e de amizade.

2. A qualidade fundamental de Sylvio Marcondes foi sempre o rigor lógico de seu pensamento, que se evidenciou exuberante nas suas aulas, desde o primeiro momento, e durante todo o seu magistério nesta Faculdade, como livre-docente e catedrático de Direito Comercial, colocando-o bem cedo entre os mais destacados juristas brasileiros de nosso tempo. Foi esse rigor lógico, com a resultante lúcida exposição dos temas de que tratava, que sempre impressionou profundamente os seus alunos; ao falar dele, sempre com saudade, mesmo anos depois de deixarem a Escola e já na plena maturidade e pujança de sua vida profissional, voltam eles inevitavelmente a esse aspecto de sua personalidade.

- Discurso proferido pelo Professor Mauro Brandāo Lopes, em homenagem póstuma ao Professor Sylvio Marcondes, no quadragésimo dia de seu falecimento, ocorrido em 3 de outubro de 1980. 
esse aspecto que, acima de qualquer outro, lembrou um seu antigo discípulo, o Professor Fábio Konder Comparato, ao saudá-lo por ocasião da outorga, que há um ano e meio lhe fez a Congregação da Faculdade de Direito, do título de Professor Emérito; notou então Fábio Comparato a "sedução que sobre o (seu) espírito exerceram, desde as primeiras aulas, a ordem lógica, a fluência de exposição, e a capacidade sistemática" de Sylvio Marcondes, observando mais que ele "convidava de pronto o estudante a entender a racionalidade do direito positivo, sob o seu aspecto estrutural", por meio de explanação de conceitos e normas, não "com fundamento apenas na tradição e na autoridade, mas na grande perspectiva do sistema jurídico"

O rigor lógico de seu pensamento aliava-se, contudo, a outro traço notável da inteligência de Sylvio Marcondes - a sua indiscutível capacidade de apreender lucidamente, e de incorporar à sua análise, o fundamento econômico de institutos jurídicos, que, assim, na sua obra, nunca se divorciaram. Sempre construiu Sylvio Marcondes, na verdade, o seu pensamento jurídico diante da "realidade" inquietante e inexorável dos fatos econômicos, de modo que fez sempre trabalho pioneiro, projetando mesmo no futuro, com freqüência, essa realidade, de modo a influenciar ao mesmo tempo o direito e a economia. Foi o que ocorreu no seu trabalho sobre o Aceite Bancário, que tem o significativo subtítulo de "Estudo Jurídico e econômico do crédito de aceitação das sociedades financiadoras para negócios de prazo médio", trabalho de subseqüente e inegável influência sobre o papel das hoje denominadas "letras financeiras", parte integrante da política governamental referente ao financiamento do mercado de bens duráveis.

E essa mesma profícua aliança de duas aptidões, de jurista e de observador cuidadoso e preciso da realidade econômica, que tão bem se entrosam (mas que raramente se encontram no mesmo homem), explica-a outra faceta da personalidade de Sylvio Marcondes - a sua reconhecida capacidade de empresário, que durante longos anos o prendeu a usinas de açúcar, de cuja fundação participara e a cuja administração pertenceu até a sua morte.

Essa capacidade, na verdade, logo cedo se revelou quando na direção de estabelecimento de ensino particular, dando-lhe a necessária vivência para, aliada à sua posterior experiência universitária, fazer com autoridade a incisiva análise, que se contém na sua aula inaugural do ano letivo de 1958 sobre 
Autonomia Universitária e Pesquisa Científica, ainda hoje de inegável relevância, porque afirma a necessidade de livre e descomprometida pesquisa científica, sem a qual, acrescento eu (p.orque é conclusão claramente implícita no trabalho), é inevitável a estagnação do ensino e a deterioração da própria Universidade.

E foi essa mesma preocupação com a pesquisa que levou Sylvio Marcondes, juntamente com outros insignes mestres desta Faculdade, a fim de receber doação da biblioteca de Tullio Ascarelli, instrumento valioso para aquela tarefa fundamental, a estruturar o "Instituto Brasileiro de Direito Comercial Comparado e Biblioteca Tullio Ascarelli" como um centro de "estudos e pesquisas de direito comercial comparado", devendo editar revista "para dar-lhes ampla divulgação", hoje a Revista de Direito Mercantil, Industrial, Econômico e Financeiro, publicada em colaboração com a Revista dos Tribunais. $\mathrm{E}$ nesse contexto não me parece possível omitir menção de importantíssima característica da produção jurídica desta Escola, conseqüência pelo menos parcial dessa preocupação de Sylvio Marcondes com a pesquisa de direito comparado, que acabou por contagiar todos os professores de seu Departamento - a esmagadora maioria de seus cursos de pós-graduação inserem-se nessa perspectiva, são assim credenciados e assim ministrados, imprimindo aspecto inconfundível aos trabalhos publicados em todos os níveis, de dissertações de mestrado a dissertações de professores titulares.

3. A atividade de todo jurista é necessariamente vária, mas por mais complexa que se apresente preside-a sempre o traço dominante de sua personalidade. Sylvio Marcondes, em todas as suas múltiplas atividades, como empresário, advogado, professor, monografista, parecerista, e autor de anteprojetos legislativos, foi sempre o pensador lúcido que isolava o ponto central de cada questão, estabelecia as suas relações necessárias com questões vizinhas ou paralelas, e lhe dava a solução adequada, que logo a todos se impunha. Essa qualidade de lucidez e de rigor lógico, não a trouxe ele somente ao ensino, ou aos seus casos profissionais, ou à sua pesquisa jurídica consubstanciada nas valiosas monografias que escreveu, ou aos estudos reunidos nos últimos anos em dois grandes volumes, aos quais outros se deveriam seguir, mas ainda à sua contribuição para o futuro direito brasileiro, consistente de anteprojetos de leis ínsitas em reformas legislativas básicas. Por meio de toda a sua obra, como notou o Professor Oscar Barreto Filho, em homenagem que lhe prestou por motivo de sua aposentadoria em fevereiro de 1976, e publicada na Revista de 
Direito Mercantil, exerceu Sylvio Marcondes "inconteste hegemonia entre os comercialistas do país".

Essa inconteste hegemonia, contudo, é bom que se observe, deveu-se à alta qualidade de seu trabalho, e não ao número de suas publicações, ou de seus pareceres, embora numerosos. Sylvio Marcondes, como podem testemunhar todos os que o conheceram, foi homem de extrema cautela e de impressionante reserva, tanto no falar como no escrever, não se pronunciando sobre questão alguma senão depois de paciente pesquisa e longa reflexão. Essa reserva, aliada a estritos e rigorosos critérios de juridicidade, levava-o às vezes, além da expectativa normal de todo cliente, a demorar a sua decisão sobre se aceitava ou não determinado parecer, para afinal, quando já o candidato a consulente à beira da exasperação, recusá-lo com motivos sempre impossíveis de afastar. E observe-se que o número dos pareceres recusados de muito sobrepujou o dos aceitos.

À conta de reserva e cautela talvez fosse de se levar também no seu entender, para jurista de tão grande nomeada, o restrito número de artigos que escreveu e de palestras que pronunciou, notadamente já na sua idade madura; e se hesito em fazer a afirmação direta e incisiva, preferindo a afirmação condicional, não me furto de pelo menos sugerir que o fato não somente tinha que ver com a sua reserva, que, no caso de palestras, o fazia fugir de pronunciamentos públicos, mas também e principalmente com a sua cautela, que, num caso e outro, artigos e conferências, o fazia evitar pronunciamentos apressados e incompletos, inevitáveis quando feitos sob a pressão de prazos e datas. Preferiu sempre Sylvio Marcondes a monografia e o estudo de âmbito mais restrito, mas claramente delimitado, que permitiam num e outro caso reflexão mais calma e mais detida ponderação. Toda a questão prendia-se, na verdade, ao seu entranhado amor à lógica jurídica e à precisão de conceitos, que o impediam de trabalho apressado e menos exato. Embora distante o paralelo, no tempo e no espaço, não vejo outro, que melhor a ele se possa aplicar, do que a antiga tradição da Universidade de Cambridge, na Inglaterra, de que dá notícia Stephen Neill, teólogo notável, segundo o qual se condenava o trabalho acadêmico que se pudesse fazer nalguns poucos anos, e só se dava apoio a projetos de toda uma vida que resultasse em monografia compacta e definitiva.

Nos seus trinta e cinco anos de magistério, desde o concurso de livre-docência em 1941 até a aposentadoria em 1976, 
deu-nos Sylvio Marcondes uma obra de extraordinária amplitude e valor. As monografias, que apresentou aos concursos de livre-docência e de cátedra, são trabalhos pioneiros no Brasil, como tais reconhecidos por todos. Constitui o primeiro, sobre a sociedade de responsabilidade limitada, um estudo de direito comparado, no meu entender até hoje, nesse aspecto, não igualado no Brasil; nele, a partir de análise do tipo societário em vários sistemas nacionais, entre os quais o brasileiro, estabeleceu Sylvio Marcondes o seu conceito genérico, jurídico e econômico, para depois confrontar, com extraordinária felicidade, o instituto brasileiro e os dos países estrangeiros de início estudados. Já a segunda monografia, sobre a limitação da responsabilidade do comerciante individual, alcançou repercussão internacional, como também notou Fábio Konder Comparato, reconhecida por Ângelo Grisoli como tendo merecido lugar de destaque na literatura mundial. E é preciso observar que neste trabalho se inserem, como partes integrantes de uma linha de argumento rigorosamente desenvolvida, os grandes temas que o seu autor retomaria em outros trabalhos, notadamente o da empresa e o da personalidade de corporações e fundações; e que nele ainda se encontra o primeiro tratamento rigoroso, no direito brasileiro, da natureza dualista da obrigação e da teoria do patrimônio.

Mas não é este o momento para análise detalhada da obra de Sylvio Marcondes, que, na sua variedade e amplitude, está a exigir apreciação compreensiva, dada a sua unidade e coerência, em que se pesem, no seu conjunto, as suas características básicas. Fez ele mesmo, contudo, uma primeira tentativa, embora parcial. No seu discurso de agradecimento, ao lhe ser outorgado o título de Professor Emérito, focalizou Sylvio Marcondes, no contexto de sua obra, o fenômeno da empresa, em suas implicações econômicas e jurídicas, para notar que tratara já do tema desde a sua dissertação de livre-docência, na qual, na distinção entre o quotista e o administrador, fizera já presente a figura do empresário, em contraposição à do capitalista, e depois ao longo de toda a sua vida de jurista, notadamente na elaboração do anteprojeto e do projeto que em 1945 resultaram na atual lei falimentar, "o mais longevo dos diplomas falimentares brasileiros", na dissertação com que concorrera à cátedra, no anteprojeto do Código de Obrigações que apresentou em 1964 como relator da matéria concernente a sociedades e exercício da atividade mercantil e, afinal, em 1972, novamente como relator do livro concernente à atividade negocial, no atual Projeto de Código Civil. Mostrou então Sylvio Marcondes que, nessa sua longa trajetória, preocupou-se 
em tornar precisos os conceitos de empresa e de empresário, configurando solução do fenômeno da empresa, que não era "simples traslado de concepções vigorantes no direito comparado, mas, sim, solução que se preconiza para o direito brasileiro", substituindo o atual sistema ultrapassado.

E este último aspecto da obra de Sylvio Marcondes, a que ele próprio se referiu com tanta propriedade, que quero retomar por um instante, diante de sua extraordinária relevância - a sua colaboração às reformas legislativas brasileiras. As qualidades de Sylvio Marcondes, a que aludi de início, o rigor lógico de seu pensamento e a sua inegável capacidade de apreender, incorporando-a à sua análise, o fundamento econômico de institutos jurídicos, faziam dele um extraordinário projetista de leis. $\mathrm{E}$ em reconhecimento de tal inegável qualidade foi que o convidaram a participar de várias Comissões. Assim, quanto aos trabalhos que levaram à edição da atual Lei de Falências, participou de todas as suas etapas, tendo sido Presidente e Relator da Comissão Mista nomeada em 1940 por associações de classe e pelo Instituto dos Advogados de São Paulo, membro da Comissão Ministerial formada em 1943, e membro da Comissão Ministerial organizada em 1945, cujo anteprojeto se converteu afinal na lei vigente. Foi autor do Anteprojeto de Código de Obrigações, na parte relativa às sociedades e ao exercício da atividade mercantil, apresentado em 1964 ; e membro da Comissão Revisora do Projeto de Código de Obrigações, remetido ao Congresso em 1965. Foi afinal, de 1969 a 1972, membro da Comissão Revisora do Código Civil Brasileiro, na qual relatou o livro sobre a atividade negocial, que teve seu Anteprojeto convertido no Projeto de Lei n. ${ }^{\circ} 634$, de 1975, hoje no Congresso Nacional.

o livro sobre a atividade negocial, de sua autoria, convém que se afirme claramente, é trabalho de extraordinária valia, mesmo que, contra toda expectativa, o Projeto não venha a se converter em lei. Nele, a figura do empresário liga-se a atividade econômica organizada, vale dizer, à empresa, considerada "unidade econômica de produção", que substitui assim, nas palavras da Exposição de Motivos, de autoria do Professor Miguel Reale, o "tormentoso e jamais determinado conceito de ato de comércio" Mas, e principalmente, ao empresário, pessoa física ou jurídica, titular da empresa, prende-se um sistema societário, de características novas, e de ainda insuspeitada relevância para o direito brasileiro do futuro; com Sylvio Marcondes uma nova etapa do direito brasileiro inaugura-se, de tal sorte, sem que tenha até agora merecido de juristas pátrios um estudo de profundidade. 
4. Resta-me ainda dizer de Sylvio Marcondes algumas poucas palavras, já agora sem mesmo a ficção de que falo também em nome de outros. O traço de reserva pessoal, tão fortemente característico de Sylvio, perdõem-me a força de expressão, mantinha mesmo os seus amigos à distância, disso sem que ele próprio se desse conta, e muitas vezes com grande mágoa sua. Os seus amigos eram, assim, seus amigos, de certo modo, apesar dele, o que equivale a dizer que eram sempre verdadeiros amigos, que ele conservava sem esforço, indefinidamente. Sylvio tinha amigos, e amigos de verdade, amigos "de horas amargas", os únicos verdadeiros, que vinham de sua mocidade, e isso muito poucos de nós pode dizer. $\mathrm{E}$ ele os reconhecia como amigos, não por palavras, que, sempre reservado, era o avesso do homem comunicativo e aberto, mas por atos, reveladores às vezes de surpreendente emoção. Por tudo isso, nenhum de seus amigos sabia calcular o número de seus amigos. Eu era um deles, e para mim, como para todos os outros, estou certo, ele deixou um grande vazio. 